\title{
The potential role of protein leverage in the US obesity epidemic
}

Kevin D. Hall, PhD

Running Title: Protein leverage and population obesity

Names for PubMed indexing: Hall.

Funding: $\mathrm{KDH}$ is supported by the Intramural Research Program of the National Institutes of Health, National Institute of Diabetes and Digestive and Kidney Diseases.

Correspondence should be addressed to:

Kevin D. Hall, Ph.D.

National Institute of Diabetes \& Digestive \& Kidney Diseases,

12A South Drive, Room 4007

Bethesda, MD 20892

kevinh@niddk.nih.gov

Conflict of interest disclosure statement: None of the authors have conflicts of interest

Revision Date: January 28, 2019

Word Count: 543 


\begin{abstract}
The protein leverage model of obesity posits that decreasing the protein content of the diet leads to compensatory increases in total energy intake to maintain an absolute amount of protein consumed. Increased energy intake thereby results in weight gain. According to data from food balance sheets from the United Nations Food and Agriculture Organization, while the absolute protein content of the US food supply has increased since the early 1970s, the fraction of available calories from protein has decreased by $\sim 1 \%$ due to greater increases in available carbohydrate and fat. Surprisingly, even such a small decrease in the protein fraction of the food supply has the potential to result in large increases in energy intake according to the protein leverage model. Therefore, while the protein leverage effect is unlikely to fully explain the obesity epidemic, its potential contribution should not be ignored.
\end{abstract}


The protein leverage model of obesity (1) posits that decreasing the protein content of the diet leads to compensatory increases in total energy intake to maintain an absolute amount of protein in the diet. Increased energy intake thereby results in weight gain. In a recent Perspective article on the role of the food environment in obesity (2), I concluded that the protein leverage model was unlikely because the amount of protein in the US food supply has increased over the past several decades and two experimental studies in humans failed to detect a short-term increase in ad libitum energy intake when a low protein diet was compared to a moderate protein diet $(3,4)$, although one previous study supported such an effect (5).

However, I failed to appreciate the potential importance of the seemingly small $\sim 1 \%$ dilution of protein availability as a fraction of total available calories in the US food supply due to greater absolute increases in carbohydrate and fat. After all, how could such a tiny decrease in the proportion of available calories as protein possibly be meaningful?

To quantitatively investigate this issue, I derived how protein leverage could affect the relationship between total energy intake, I, absolute protein energy intake, $\mathrm{P}$, and the fraction of total energy as protein, $\mathrm{p}$. By definition: $\mathrm{P}=\mathrm{Ip}$ and deviations, $\mathrm{dP}$, from baseline protein energy intake are given by the differential form:

$$
d P=I d p+p d I
$$

The following equation is a simple representation of the protein leverage concept:

$$
d P=(1-L) I d p
$$

The extent of protein leverage, $L$, varies between no protein leverage $(L=0)$ whereby changing the protein fraction of total energy by dp results in a passive change in absolute protein energy intake of $\mathrm{dP}=\mathrm{Idp}$. Alternatively, perfect protein leverage $(\mathrm{L}=1)$ results in no change in absolute protein energy 
intake: $\mathrm{dP}=0$. Combining the above equations to eliminate $\mathrm{dP}$ results in the following differential equation relating I and $\mathrm{p}$ :

$$
\frac{d I}{I}=-L \frac{d p}{p}
$$

Integrating both sides gives:

$$
\ln (I)=-L \times \ln (p)+C
$$

where $\mathrm{C}$ is the integration constant. Exponentiating both sides results in the following power-law solution:

$$
I=K p^{-L}
$$

where the constant $K=\exp (C)$ is determined by the baseline energy intake (assumed to be $2500 \mathrm{kcal} / \mathrm{d}$ corresponding to a physical activity level of 1.6) at the baseline protein energy fraction (assumed to be $12.8 \%)$.

Figure $1 \mathrm{~A}$ plots the relationship between energy intake and the protein fraction for different assumptions of the amount of protein leverage. Interestingly, for perfect protein leverage $(L=1)$, even the very small decrease in the fraction of available protein calories since the early 1970 s predicts a substantial increase in energy intake. Nevertheless, the increase in energy intake predicted by the protein leverage model was far below the observed increase in total US food supply daily per capita calories. Figures $1 \mathrm{~B}$ and $1 \mathrm{C}$ illustrate that the predicted increase in total energy intake assuming perfect protein leverage was insufficient to fully explain the rise in mean adult body weight as estimated by a validated mathematical model of human body weight dynamics (6). Nevertheless, Figure $1 \mathrm{C}$ shows that even a modest degree of protein leverage $(L=0.5)$ may have contributed $\sim 33 \%$ of the average adult weight gain during the US obesity epidemic. Therefore, while questions remain about the protein 
leverage concept in human nutrition, the potential importance of protein leverage on the rise in obesity prevalence should not be ignored.

\section{References}

1. Simpson SJ, Raubenheimer D. Obesity: the protein leverage hypothesis. Obes Rev 2005;6: 133142.

2. Hall KD. Did the Food Environment Cause the Obesity Epidemic? Obesity (Silver Spring) 2018;26: 11-13.

3. Martens EA, Lemmens SG, Westerterp-Plantenga MS. Protein leverage affects energy intake of high-protein diets in humans. Am J Clin Nutr 2013;97: 86-93.

4. Martens EA, Tan SY, Dunlop MV, Mattes RD, Westerterp-Plantenga MS. Protein leverage effects of beef protein on energy intake in humans. Am J Clin Nutr 2014;99: 1397-1406.

5. Gosby AK, Conigrave AD, Lau NS, Iglesias MA, Hall RM, Jebb SA, et al. Testing protein leverage in lean humans: a randomised controlled experimental study. PLoS One 2011;6: e25929.

6. Hall KD, Sacks G, Chandramohan D, Chow CC, Wang YC, Gortmaker SL, et al. Quantification of the effect of energy imbalance on bodyweight. Lancet 2011;378: 826-837.

\section{Figure Legend}

Figure 1. A) Increases in available calories in the US food supply since 1973 as a function of the protein fraction in the food supply $(\bullet)$ as determined by the United Nations Food and Agriculture (FAO) food balance sheets (http://www.fao.org/faostat/en/\#data/FBS). The blue and orange curves show the increase in energy intake associated with the decreased protein fraction of the food supply as predicted by the protein leverage model assuming perfect leverage $(L=1)$ or modest leverage $(L=0.5)$, respectively. B) Time course of the average adult energy intake increases as predicted by a validated mathematical model of human body weight dynamics that fully explains the observed average weight changes as well 
as the increases in energy intake predicted by the protein leverage model. C) Observed average adult weight changes according to the National Health and Nutrition Examination Survey (NHANES) and the predicted weight changes due to the increasing energy intake according to the protein leverage model. 
A

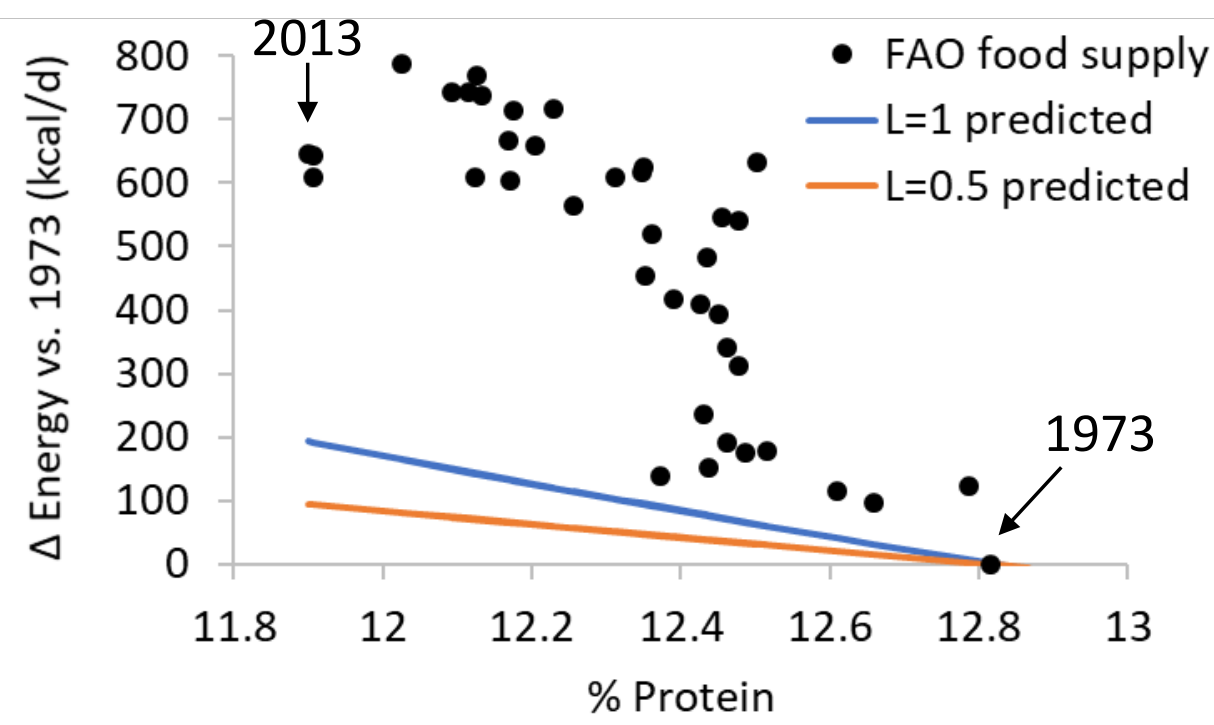

B
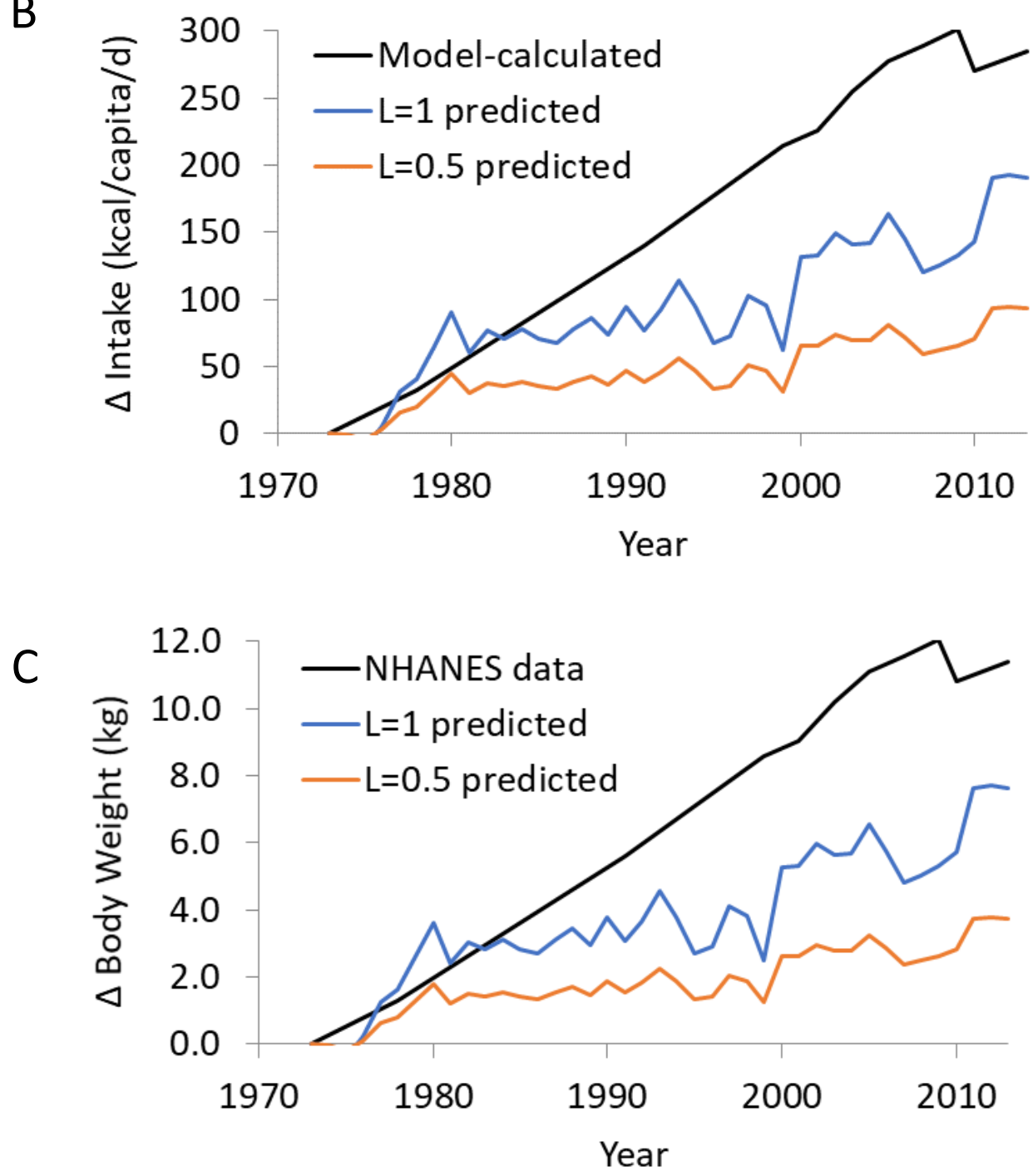

Figure 1 